\title{
Atenolol increases dental mineralization in male offspring of treated hypertensive rats and normotensive rats
}

\section{Gracieli Prado ELIAS ${ }^{(a)}$ \\ Heitor Ceolin ARAUJO(b) \\ Kikue Takebayashi SASSAKI(c) \\ Alberto Carlos Botazzo DELBEM(b) \\ Cristina ANTONIALI(c)}

(a) Universidade Federal de Juiz de Fora - UFJF, Juiz de Fora Dental School, Department of Pediatric Dentistry and Public Heatlh, Juiz de Fora, MG, Brazil.

(b) Universidade Estadual Paulista - Unesp, School of Dentistry, Department of Preventive and Restorative Dentistry, Araçatuba, SP, Brazil.

(c) Universidade Estadual Paulista - Unesp, School of Dentistry, Department of Basic Sciences, Araçatuba, SP, Brazil.

Declaration of Interests: The authors certify that they have no commercial or associative interest that represents a conflict of interest in connection with the manuscript.

\section{Corresponding Author:}

Cristina Antoniali

E-mail: cristina.antoniali@unesp.br

https://doi.org/10.1590/1807-3107bor-2020.vol34.0086

Submitted: March 10, 2020

Accepted for publication: June 2, 2020

Last revision: June 16, 2020

\begin{abstract}
This study evaluates how atenolol affects dental mineralization in offspring of female spontaneously hypertensive rats (fSHR) and normotensive Wistar rats (fW). fSHR and $\mathrm{fW}$ were treated with atenolol $(100 \mathrm{mg} / \mathrm{Kg} /$ day, orally) during pregnancy and lactation. Non-treated fSHR and fW were the control groups. Enamel and dentin hardness were analyzed (Knoop, $15 \mathrm{~g}$ load, 10s) in mandibular incisor teeth (IT) and molar teeth (MT) obtained from the male offspring of atenolol-treated and non-treated fWistar and fSHR. Data were analyzed by ANOVA, followed by Tukey post hoc test $(\mathrm{p}<0.05)$. Atenolol reduced the arterial blood pressure (SBP) in fSHR, but it did not change the SBP in $\mathrm{fW}$. The offspring of non-treated fSHR had lower enamel (IT and MT) and dentin (IT) hardness than the offspring of non-treated fW ( $p<0.05)$. Atenolol increased enamel and dentin hardness in the IT obtained from the offspring of fSHR and fW $(\mathrm{p}<0.05)$, but the offspring of fSHR presented higher values $(p<0.05)$. Atenolol did not alter enamel width in the IT obtained from any of the groups, but it increased enamel and dentin hardness in the IT obtained from the offspring of fSHR and fW. Atenolol affected the IT obtained from the offspring of fSHR. Atenolol increased only enamel hardness in the MT obtained from the offspring of $\mathrm{fW}$. In conclusion, maternal hypertension reduces tooth hard tissues, and treatment with atenolol increases tooth hardness in male offspring of hypertensive and normotensive female rats.
\end{abstract}

Keywords: Dental Enamel; Dentin; Hardness; Atenolol; Hypertension.

\section{Introduction}

During pregnancy, complications such as hypertension, diabetes, infection, and nutritional deficiencies have been associated with problems in dental formation and hypoplastic enamel in children. ${ }^{1}$ In humans, the deciduous and permanent teeth of children of hypertensive mothers present reduced crown diameter. ${ }^{2}$ In animals, the male offspring (30 days old) of spontaneously hypertensive rats (SHR) have mandibular incisor teeth with decreased enamel and dentin hardness as compared to the male offspring of normotensive Wistar rats. ${ }^{3}$ Poor mineralization of these dental structures might favor the condition described as 
amelogenesis imperfecta, which is observed in the teeth of Stroke-prone SHR (SHRSP). ${ }^{4}$ This condition originates from the underdevelopment of dental ameloblasts, which are involved in enamel matrix production, re-absorption, and degradation and in calcium transport for mineralization. ${ }^{5}$ The mechanisms underlying these alterations have not been established yet, but clinical evidence and experimental studies have associated dental mineralization defects with variations in serum calcium concentrations. Like hypertensive humans, SHR have abnormal calcium metabolism, including low serum calcium and high serum parathyroid hormone levels. ${ }^{6}$

Blood pressure monitoring is an essential part of prenatal care during pregnancy. The main cause of fetal and maternal mortality during pregnancy is hypertension. ${ }^{7}$ Cardiovascular drugs, such as antihypertensive drugs, are often used to treat maternal and fetal conditions during pregnancy. Mothers could also require continued postpartum drug therapy. ${ }^{7} \beta$-adrenergic blockers can effectively manage high blood pressure during pregnancy, ${ }^{8}$ but treatment with atenolol during the first trimester of pregnancy or during conception may be associated with low weight in children, ${ }^{9}$ intrauterine growth retardation, decreased fetal/birth weight in the absence of congenital malformations, and postnatal effects like decreased weight gain in tested animal species (rats and rabbits) and humans..$^{10}$ Nevertheless, the breeding size or weight of 30-day-old offspring of SHR and Wistar rats did not change for mother rats treated with atenolol during pregnancy and lactation. ${ }^{11}$

Therapy with $\beta$-adrenergic blockers could increase the bone mass density in animals ${ }^{12,13}$ and elderly human patients with hypertension..$^{14,15}$ Although bones and teeth are tissues with peculiar characteristics, they share a few similarities. For example, the fact that odontoclasts re-absorb the dentin extracellular matrix and cementum in teeth resembles the activity of osteoclasts. In addition, the tooth tissue expresses molecules that participate in bone re-absorption in odontoblasts, ameloblasts, and pulp cells ${ }^{16}$ as well as in early tooth primordia cells. ${ }^{17}$ However, relatively little attention has been given to whether treatment with atenolol during the organogenesis period affects mineralized tissues. Therefore, we have hypothesized that treatment with atenolol during pregnancy and lactation not only reduces the blood pressure in SHR rats, but also increases enamel and dentin hardness in male offspring of SHR.

In this sense, this study aimed to evaluate how atenolol impacts dental mineralization in male offspring of female SHR treated with this compound during pregnancy and lactation.

\section{Methodology}

\section{Animals}

The experiments were conducted with 30-dayold male offspring ( $\mathrm{n}=10 /$ group) of female spontaneously hypertensive rats (fSHR) and female normotensive Wistar rats (fW). During pregnancy and lactation, the female rats were kept in a bioterium with controlled temperature $\left(22-24^{\circ} \mathrm{C}\right)$ and light cycle ( $12 \mathrm{~h} /$ light and $12 \mathrm{~h} /$ darkness), and standard food and water were available ad libitum. After birth, their offspring were housed in the same conditions. fSHR and $\mathrm{fW}$ were treated with atenolol $100 \mathrm{mg} / \mathrm{Kg} /$ day diluted in a predetermined water volume that they ingested per day. For the fSHR and fW control groups, the animals received the same water volume without the drug. The experimental protocols were approved by the Animal Research Ethics Committee of the School of Dentistry of Araçatuba, UNESP (process n. 37/03).

\section{Arterial blood pressure}

The systolic blood pressure (SBP) in fSHR and $\mathrm{fW}$ was recorded during pregnancy (days: $0,7,14,20$ ) and lactation (days: 7, 14, 21, 28) by tail plethysmograph adapted for measurements in rats (plethysmograph Physiiograph® MK-III-S - Narco Bio-Systems / Houston, Texas, USA). Only the fW with SBP around $112 \mathrm{mmHg}$ and the fSHR with SBP equal to or higher than $150 \mathrm{mmHg}$ were used in the experiments. Pregnancy was determined by the presence of spermatozoa in the vaginal smears of the female rats; the day when spermatozoa were observed in the vaginal smear was labeled as day zero of pregnancy. 


\section{Tooth removal}

Male offspring (30-day-old) of atenolol-treated and non-treated $\mathrm{fSHR}$ and $\mathrm{fW}$ were killed with excess anesthesia. The mandibular incisor teeth (IT) and first molar teeth (MT) were removed from the dental arch. Only the IT were removed without concomitant bone tissue removal (Figure 1).

\section{Enamel and dentin mineralization}

The mandibular IT and MT were embedded in acrylic resin (Figure 2, A and B), and the specimens were ground and polished for cross-sectional hardness analysis with a microhardness tester (Shimadzu HMV-2000, Shimadzu Co., Kyoto, Japan) equipped with a Knoop indenter and a static load

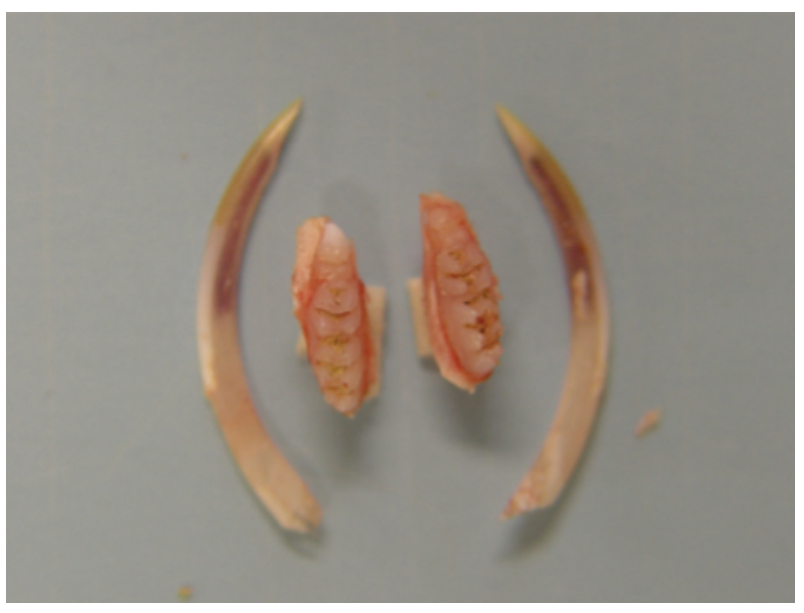

Figure 1. Mandibular incisor teeth and first molar teeth removed from male offspring of female rats.

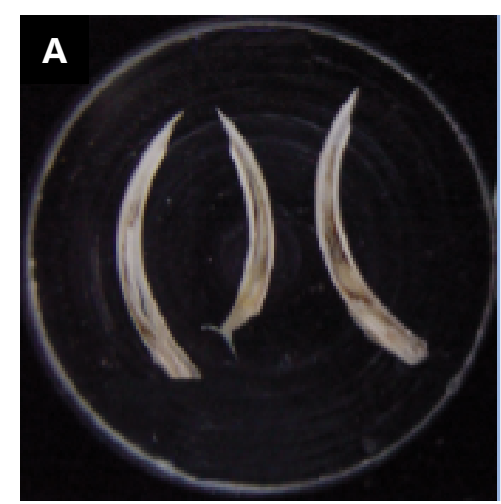

of $15 \mathrm{~g}$ for $10 \mathrm{~s}$ and connected to the software for image analysis CAMS-WIN (New Age Industries, Horsham, USA). Three indentation sequences were performed in the IT; the first was conducted $200 \mu \mathrm{m}$ from the incisal edge, and the other two $500 \mu \mathrm{m}$ away from each other. At each sequence, three indentations were made at 20,40, and $60 \mu \mathrm{m}$ from the external enamel surface (Figure 3). For the dentin, the same sequence was followed, and the three indentations were achieved from the dentin-enamel junction. In the first MT, the same number of indents was performed in the enamel and dentin between the first and the second molar. Three sequences of indentations were made $45 \mu \mathrm{m}$ away from each other and from the cusp edge. The mean hardness values, from the three sequences of all indentations in the enamel and dentin for the incisor and molar teeth, were calculated for each animal and expressed as $\mathrm{kgf} / \mathrm{mm}^{2}$.

\section{Histomorphometric analysis of the enamel and dentin thickness of the incisal and medium thirds of the incisor teeth}

Ten blocks of resin (10 incisors) were selected from each experimental group. The images of the incisal and medium thirds of the enamel in the IT were captured by a digital camera coupled to an optical microscope (50-time amplification) and saved on a computer. The accurate location of the medium third was determined by measuring the entire tooth length with a digital pachymeter and marking a dot corresponding to half of the measured piece. The

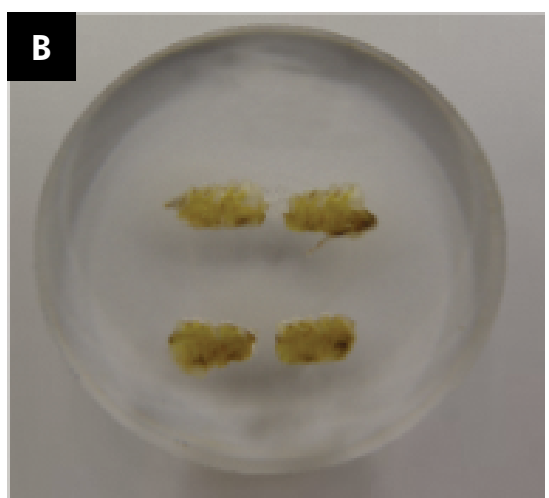

Figure 2. Mandibular incisor teeth (A) and first molar teeth (B) embedded in acrylic resin. 


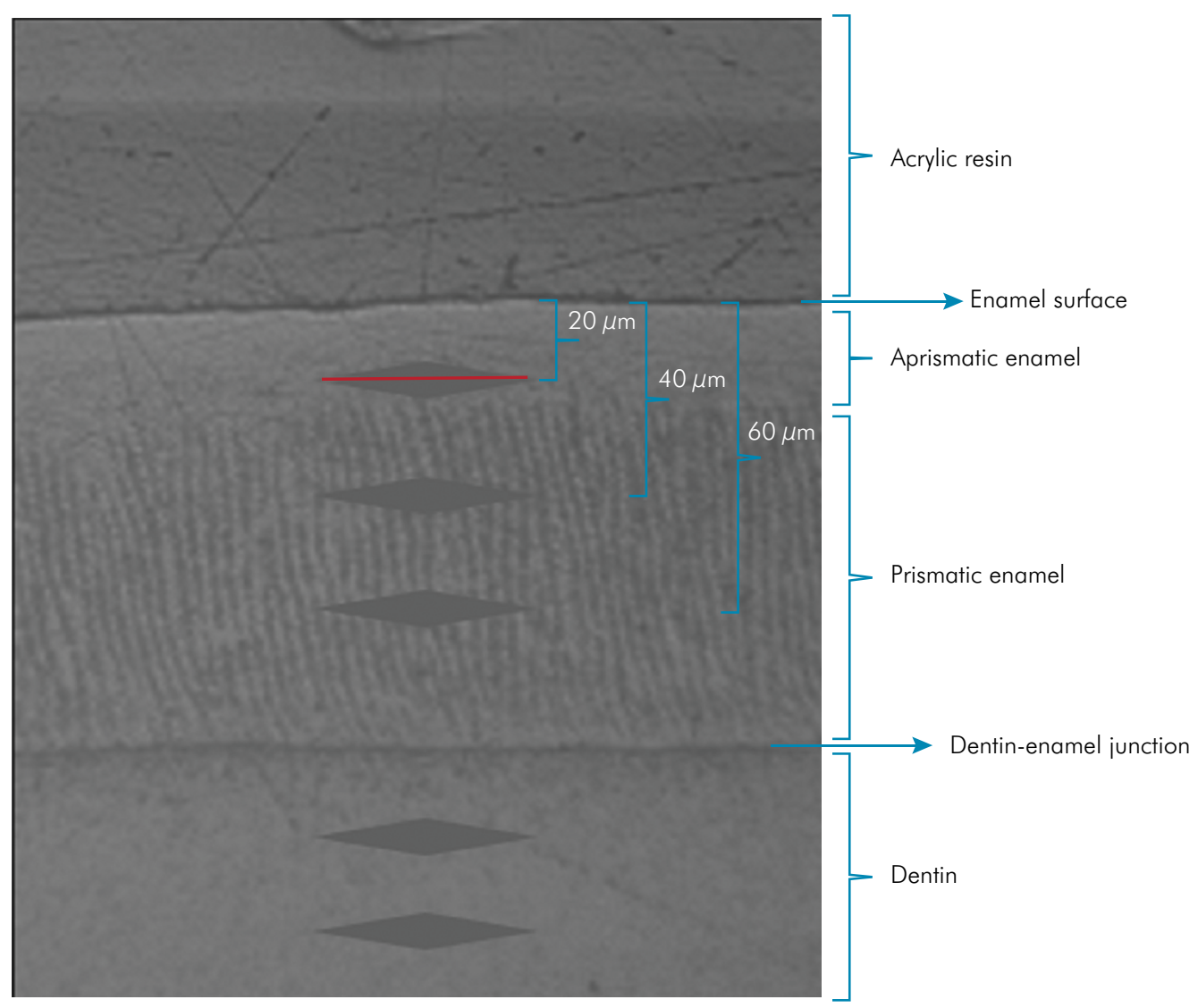

Figure 3. Indentations made in enamel and dentin of the teeth removed from male offspring.

thickness $(\mu \mathrm{M})$ was analyzed with the "ImageLab 2000" software (Diracon Bio Informática Ltda., Vargem Grande do Sul, Brazil).

\section{Statistical analysis}

The normality (Kolmogorov-Smirnov test) and homogeneity (Cochran test) of the results were evaluated (GMC 2002 Version software) and submitted to one-way analysis of variance (ANOVA) with factorial scheme followed by Tukey post hoc test. The level of significance was taken as $\mathrm{p}<0.05$ and the results are expressed as mean \pm standard deviation (SD).

\section{Results}

The SBP was higher $(\mathrm{p}<0.05)$ in fSHR than in $\mathrm{fW}$ throughout the pregnancy (0-20 days) and lactation (27-48) periods (Table 1). The SBP reduced on the 20th $(139 \mathrm{mmHg} \pm 9)$ day of pregnancy in fSHR, but the value was still higher $(p<0.05)$ when compared to the value measured in $\mathrm{fW}$ on the same day. In $\mathrm{fW}$, the SBP reduction was associated with the end of pregnancy $(101 \mathrm{mmHg} \pm 4$, day 20 ), but this value did not differ from the value measured on day zero. Treatment with atenolol (100 mg/Kg/day) did not change the SBP in $\mathrm{fW}$, but it significantly decreased $(p<0.05)$ the SBP in fSHR. This effect could be observed from the 7 th day of pregnancy until the end of lactation. Atenolol abolished the SBP variations observed during pregnancy and lactation in fSHR. Under the atenolol antihypertensive effect, the SBP values in fSHR were closer to, but still higher than the SBP values observed in $\mathrm{fW}(\mathrm{p}<0.05)$.

Structural changes were observed in the IT and MT obtained from the male offspring of atenololtreated and non-treated fSHR and fW (Table 2). Enamel and dentin hardness were lower in the IT obtained from the offspring of fSHR as compared to the IT obtained from the offspring of $\mathrm{fW}(\mathrm{p}<0.05)$. 
Table 1. Mean values (SD) of systolic blood pressure in female Wistar rats and female SHR, non-treated and treated with atenolol $(+$ Atenolol), during the periods of pregnancy and lactation.

\begin{tabular}{|c|c|c|c|c|c|c|c|c|}
\hline \multirow{2}{*}{ Groups } & \multicolumn{4}{|c|}{ Pregnancy } & \multicolumn{4}{|c|}{ Lactation } \\
\hline & Day 0 & Day 7 & Day 14 & Day 20 & Day 7 & Day 14 & Day 20 & Day 28 \\
\hline \multirow{2}{*}{ Wistar } & $108^{\mathrm{Aa}}$ & $108^{\mathrm{Aa}}$ & $104^{\mathrm{Aa}}$ & $101^{\mathrm{Aa}}$ & $100^{\mathrm{Aa}}$ & $100^{\mathrm{Aa}}$ & $103^{\mathrm{Aa}}$ & $107^{\mathrm{Aa}}$ \\
\hline & (6) & (6) & (6) & (4) & (0) & 0 & -5 & (6) \\
\hline \multirow{2}{*}{ Wistar + Atenolol } & $105^{\mathrm{Aa}}$ & $101^{\mathrm{Aa}}$ & $101^{\mathrm{Aa}}$ & $100^{\mathrm{Aa}}$ & $100^{\mathrm{Aa}}$ & $100^{\mathrm{Aa}}$ & $100^{\mathrm{Aa}}$ & $100^{\mathrm{Aa}}$ \\
\hline & (6) & (3) & (3) & (0) & (0) & (0) & (0) & (0) \\
\hline \multirow{2}{*}{ SHR } & $181^{\mathrm{Ba}}$ & $174^{\mathrm{Ba}}$ & $170^{\mathrm{Ba}}$ & $139^{\mathrm{Bb}}$ & $155^{\mathrm{Bb}}$ & $170^{\mathrm{Ba}}$ & $177^{\mathrm{Ba}}$ & $180^{\mathrm{Ba}}$ \\
\hline & (10) & (11) & (12) & (9) & (11) & (16) & (8) & (9) \\
\hline \multirow{2}{*}{ SHR + Atenolol } & $176^{\mathrm{Ba}}$ & $149 \mathrm{cb}$ & $144^{\mathrm{Cb}}$ & $126^{c c}$ & $128^{\mathrm{cc}}$ & $128^{\mathrm{cc}}$ & $126^{\mathrm{cc}}$ & $125^{\mathrm{cc}}$ \\
\hline & (12) & (9) & (14) & (4) & (6) & (5) & (4) & (0) \\
\hline
\end{tabular}

Distinct capital letters show significant differences among the groups at the same column and the distinct lowercase letters show significant differences among the groups at same line (ANOVA, Tukey test, $p<0.05$ ).

Table 2. Mean values (SD) of hardness from incisor and molar teeth, and enamel's layer thickness of incisor teeth in male offspring of atenolol-treated and non-treated female SHR and female Wistar rats.

\begin{tabular}{|c|c|c|c|c|c|c|}
\hline \multirow{4}{*}{ Groups } & \multicolumn{4}{|c|}{ Hardness $\left(\mathrm{kgf} / \mathrm{mm}^{2}\right)$} & \multicolumn{2}{|c|}{ Enamel Thickness $(\mu \mathrm{m})$} \\
\hline & \multicolumn{2}{|c|}{ Incisors Teeth } & \multicolumn{2}{|c|}{ Molars Teeth } & \multirow{2}{*}{$\begin{array}{l}\text { Incisal } \\
\text { Third }\end{array}$} & \multirow{2}{*}{$\begin{array}{c}\text { Medium } \\
\text { Third }\end{array}$} \\
\hline & \multicolumn{2}{|c|}{$(n=10)$} & \multicolumn{2}{|c|}{$(n=10)$} & & \\
\hline & Enamel & Dentin & Enamel & Dentin & $(n=10)$ & $(n=10)$ \\
\hline \multirow{2}{*}{ Wistar } & $320.4^{\mathrm{A}}$ & $64.0^{\mathrm{A}}$ & $439.6^{\mathrm{A}}$ & $65.2^{\mathrm{A}}$ & $0.257^{A}$ & $0.076^{\mathrm{A}}$ \\
\hline & (21.8) & $(4.7)$ & $(4.1)$ & $(1.5)$ & $(0.023)$ & $(0.027)$ \\
\hline \multirow{2}{*}{ Wistar + Atenolol } & $451.2^{\mathrm{B}}$ & $103.2^{B}$ & $526.0^{\mathrm{B}}$ & $61.5^{\mathrm{A}, \mathrm{B}}$ & $0.280^{A}$ & $0.072^{A}$ \\
\hline & (23.8) & $(8.1)$ & $(4.4)$ & $(0.7)$ & $(0.079)$ & $(0.010)$ \\
\hline \multirow{2}{*}{ SHR } & $256.4^{\mathrm{C}}$ & $60.11^{\mathrm{C}}$ & $364.2^{c}$ & $60.0^{\mathrm{B}}$ & $0.201^{B}$ & $0.051^{\mathrm{B}}$ \\
\hline & $(10.2)$ & (3.1) & (3.2) & $(1.0)$ & $(0.026)$ & $(0.005)$ \\
\hline \multirow{2}{*}{ SHR + Atenolol } & $535.4^{\mathrm{D}}$ & $108.1^{\mathrm{D}}$ & $370.5^{c}$ & $62.3^{A, B}$ & $0.171^{B}$ & $0.061^{\mathrm{B}}$ \\
\hline & $(18.1)$ & (6.0) & (11.5) & $(1.6)$ & $(0.016)$ & $(0.022)$ \\
\hline
\end{tabular}

The distinct letters show significant differences among the groups at same column (ANOVA, Tukey test, $p<0.05$ ).

Treatment of pregnant rats with atenolol increased enamel and dentin hardness in the male offspring $(p<0.05)$ in both groups; however, the offspring of fSHR presented higher values $(\mathrm{p}<0.05)$. Concerning the MT, the offspring of fSHR had lower enamel and dentin hardness as compared to the offspring of $\mathrm{fW}(\mathrm{p}<0.05)$. Treatment with atenolol increased enamel hardness in the offspring of $\mathrm{fW}(\mathrm{p}<0.05)$, but the same treatment did not alter dentin hardness regardless of the rat lineage $(p>0.05)$. Enamel thickness was lower in the IT obtained from the offspring of fSHR as compared to the offspring of fW $(\mathrm{p}<0.05)$, and treatment with atenolol did not change it $(p>0.05)$.

\section{Discussion}

For the first time, the present study has shown that treatment with atenolol increases enamel and dentin microhardness of the incisor and molar teeth in the offspring of spontaneously hypertensive rats and normotensive Wistar rats. Because dental microhardness increased in the offspring of female rats treated with atenolol during pregnancy and lactation, we can guarantee that their offspring were treated with atenolol from the conception, via placental circulation, to the 30th day of life, via the mother's milk or drinking water. Therefore, the treatment period encompassed tooth development 
from the earliest formation of the epithelial thickening to cytodifferentiation and the mineralization stages, which may have been altered by atenolol.

In $\mathrm{fSHR}$, antihypertensive treatment involving oral administration of atenolol $(100 \mathrm{mg} / \mathrm{kg} /$ day $)$ was effective from the onset of pregnancy until the end of lactation. Atenolol reduced the high SBP values measured in $\mathrm{fSHR}$ during pregnancy and abolished the SBP variations observed during pregnancy and lactation as previously demonstrated by our group. ${ }^{11}$ Moreover, as previously reported, ${ }^{11,18}$ atenolol did not affect the SBP in $\mathrm{fW}$.

Despite its antihypertensive effect, atenolol did not change the physiological parameters in fSHR or their offspring during fetal and postpartum development, which corroborated previous results. ${ }^{3,11}$ However, other animal studies in which exposure to atenolol was limited to the period of major organogenesis (6-15 and 6-18 days in rats and rabbits, respectively) reported different results: signs of embryotoxicity and postnatal effect emerged at oral doses of $25 \mathrm{mg} / \mathrm{kg} /$ day or above. ${ }^{10}$

On the basis of the data obtained in the present study, atenolol increased enamel and dentin microhardness in the IT obtained from the offspring of fSHR and $\mathrm{fW}$, but the IT enamel width remained unchanged. As for the MT, atenolol impacted dental mineralization differently in hypertensive and normotensive rats. Atenolol increased enamel microhardness in the MT obtained from the offspring of $\mathrm{fW}$ (dentin microhardness in the MT remained unaltered in this case) and enamel and dentin microhardness in the IT obtained from the offspring of fSHR. These findings showed that atenolol affected enamel and dentin microhardness in the IT mainly. The biological reaction of a tissue depends on whether local or systemic factors can impact formative cells during development. If such disturbances occur, they are automatically reflected and recorded in the growing structure. ${ }^{19}$ In the IT of rats, enamel and dentin are continuously being apposed by cells that are constantly being derived from the odontogenic epithelium, which is continuously proliferating. ${ }^{20}$ In the MT of rats, the situation is different: the odontogenic epithelium has limited activity, so no new cells replace the old ones, thereby limiting tooth growth ${ }^{20}$. Furthermore, amelogenesis and dentinogenesis ${ }^{21,22}$ involve distinct mechanisms that are associated with cellular differentiation, ameloblasts and odontoblasts, extracellular matrix deposition and resorption, and calcium deposition in incisor and molar teeth, and atenolol can impact these mechanisms in different ways. However, specific studies must be conducted to test this hypothesis.

Our results also demonstrated that the effect of atenolol in the IT microhardness was potentiated in the offspring of fSHR. The higher impact of atenolol on dental microhardness in the offspring of fSHR could stem from the differences in dental microhardness observed between the groups before treatment. As demonstrated before, ${ }^{3} 30$-day-old male offspring of fSHR had markedly reduced enamel and dentin microhardness in the IT. This lack of dental mineralization could be associated with lower enamel width in the medium and incisal thirds of enamel in the IT of the offspring of fSHR. We also verified decreased enamel and dentin microhardness in the MT of these animals. In humans and animals, intrauterine growth restriction significantly contributes to increased prevalence of opaque and hypoplastic enamel later in life. ${ }^{21}$ Poor enamel mineralization might originate from underdeveloped dental ameloblasts ${ }^{5}$. Additionally, dental mineralization could be affected by reduced ionized serum calcium homeostasis ${ }^{6}$ due to lower active calcium transportation from the mother to the fetus through the placenta as well as several perinatal disturbances or alterations in serum parathormone (PTH) concentration. ${ }^{22}$ Hy pocalcemia increases PTH in SHR ${ }^{6}$. PTH secretion is also regulated by other factors such as adrenergic stimulus, vitamin $\mathrm{D}$, phosphate and magnesium ions, calcitonin, and growth hormones. ${ }^{22}$ Until now, our results have not been able to explain the mechanism underlying the dental formation alteration in the offspring of fSHR, but both hypocalcemia and increased PTH observed in fSHR could be directly related to this alteration: PTH receptors are present in odontoblasts, which suggests that odontogenesis is controlled by hormones through calcium transportation. ${ }^{23}$ Although a PTH receptor has not been found in ameloblasts, it can alter ameloblast function and maturation..$^{23}$ The antagonist effect of atenolol on 
the $\beta$-adrenergic receptors of parathyroid cells could inhibit PTH secretion and increase dental mineralization in the teeth of the offspring of fSHR fW even though calcium and PTH disturbances have not been related to normotensive rats.

Calcium plasma concentration or PTH levels cannot be suggested as a single mechanism underlying the effect of atenolol on microhardness. Studies ${ }^{13,14,15,23}$ have evidenced a molecular mechanism that explains the effect of $\beta$-blockers on mineralized tissues. The first evidences were provided by case-control clinical studies which showed that the use of $\beta$-adrenergic blockers was associated with $23-30 \%$ lower risk of vertebral or non-vertebral (hand, forearm, foot) fractures. ${ }^{14,15}$ Although the reported results were controversial, ${ }^{25}$ this effect was correlated to many experimental evidences, which pointed out that bone turnover/remodeling might be subjected to central control, with the sympathetic nervous systems acting as the peripheral effector and leptin, a hormone that is produced in fat cells, serving as the regulator of neural pathways. ${ }^{13,24}$ In the reported molecular mechanism, ${ }^{24}$ activation of a noradrenalin receptor causes osteoblasts to produce a RANK ligand (RANKL) that stimulates osteoclast formation, so $\beta$-adrenergic blockers inhibit osteoclast formation.

Rat incisor teeth grow and calcify continuously, ${ }^{20}$ so the effect of atenolol can be recorded relatively fast in this dental tissue. Experimental evidences have suggested that the sympathetic nervous system also plays an important role in mandibular bone metabolism and dental growth. ${ }^{25,26}$ Dental pulp and odontoblast cell lines express osteoprotegerin (osteoclatogenesis inhibitory factor, OPG), RANKL, and macrophage colony-stimulating factor (M-CSF) factors that are crucial for the regulation of osteoclast formation. ${ }^{16,17}$ In vivo, RANKL and OPG are located in odontoblasts, ameloblasts, and pulp cells in developing mouse teeth ${ }^{16}$ as well as in thickening and bud epithelium, internal and external enamel epithelium, and papilla mesenchyme, ${ }^{17}$ which indicates that these factors participate in tooth development. PTH downregulates OPG/OCIF (osteoclatogenesis inhibitory factor) mRNA expression in stromal cells, which could stimulate osteoclast formation. Similar to osteoclasts, odontoclasts that resorb dentin and cementum extracellilar matrix have been described. ${ }^{23}$ Altogether, these results suggest that atenolol influences molecular mechanisms involved in tooth development.

\section{Conclusion}

Our results provide further insight into the effects of hypertension and its treatment with atenolol during pregnancy and lactation. Maternal hypertension has been associated with reduced enamel and dentin microhardness in the mandibular incisor and molar teeth obtained from 30-day-old rats. Treatment of female rats with atenolol (a $\beta$-adrenergic blocker) during pregnancy and lactation increases enamel and dentin microhardness in the incisor teeth of their offspring. These data demonstrate that atenolol increases dental mineralization, and its effect is more important in teeth with continuous growth and calcification.

\section{Acknowledgments}

This study was financed by Coordenação de Aperfeiçoamento de Pessoal de Nível Superior Brasil (CAPES) - Finance Code 001, and Fundação para o Desenvolvimento da UNESP (FUNDUNESP).

\section{References}

1. Shulman JD. Is there an association between low birth weight and caries in the primary dentition? Caries Res. 2005 May-Jun;39(3):161-7. https://doi.org/10.1159/000084792

2. Garn SM, Osborne RH, McCabe KD. The effect of prenatal factors on crown dimensions. Am J Phys Anthropol. 1979 Nov;51(4):665-78. https://doi.org/10.1002/ajpa.1330510416

3. Elias GP, Santos OA, Sassaki KT, Delbem AC, Antoniali C. Dental mineralization and salivary activity are reduced in offspring of spontaneously hypertensive rats (SHR). J Appl Oral Sci. 2006 Aug;14(4):253-9. https://doi.org/10.1590/S1678-77572006000400008 
- Atenolol increases dental mineralization in male offspring of treated hypertensive rats and normotensive rats

4. Ishibashi K, lino T, Sekiguchi F. Amelogenesis imperfecta, a new dental mutation in rats. Lab Anim Sci. 1990 Jan;40(1):16-20.

5. Sasaki T, Takagi M, Yanagisawa T. Structure and function of secretory ameloblasts in enamel formation. Ciba Found Symp. 1997;205:32-46.

6. DiPette DJ, Christenson W, Nickols MA, Nickols GA. Cardiovascular responsiveness to parathyroid hormone (PTH) and PTH-related protein in genetic hypertension. Endocrinology. 1992 Apr;130(4):2045-51.

7. Fischer MB, Thingaard E, Andersen AS, Pinborg AB. [Masked hypertension during pregnancy]. Ugeskr Laeger. 2018 Jan;180(2):2-5. Danish.

8. Al Khaja KA, Sequeira RP, Alkhaja AK, Damanhori AH. Drug treatment of hypertension in pregnancy: a critical review of adult guideline recommendations. J Hypertens. 2014 Mar;32(3):454-63. https://doi.org/10.1097/HJH.0000000000000069

9. Bayliss H, Churchill D, Beevers M, Beevers DG. Anti-hypertensive drugs in pregnancy and fetal growth: evidence for "pharmacological programming" in the first trimester? Hypertens Pregnancy. 2002;21(2):161-74. https://doi.org/10.1081/PRG-120013785

10. Tabacova S, Kimmel CA, Wall K, Hansen D. Atenolol developmental toxicity: animal-to-human comparisons. Birth Defects Res A Clin Mol Teratol. 2003 Mar;67(3):181-92. https://doi.org/10.1002/bdra.10011

11. Elias GP, Sassaki KT, Delbem AC, Antoniali C. Atenolol reduces salivary activity in pups of spontaneously hypertensive and normotensive rats treated during pregnancy and lactation. Clin Exp Hypertens. 2008 Feb;30(2):133-41. https://doi.org/10.1080/10641960801931923

12. Bonnet N, Laroche N, Vico L, Dolleans E, Benhamou CL, Courteix D. Dose effects of propranolol on cancellous and cortical bone in ovariectomized adult rats. J Pharmacol Exp Ther. 2006 Sep;318(3):1118-27. https://doi.org/10.1124/ipet.106.105437

13. Takeda S. Central control of bone remodeling. Biochem Biophys Res Commun. 2005 Mar;328(3):697-9. https://doi.org/10.1016/i.bbrc.2004.11.071

14. Pasco JA, Henry MJ, Sanders KM, Kotowicz MA, Seeman E, Nicholson GC; Geelong Osteoporosis Study. Beta-adrenergic blockers reduce the risk of fracture partly by increasing bone mineral density: Geelong Osteoporosis Study. J Bone Miner Res. 2004 Jan;19(1):1924. https://doi.org/10.1359/jbmr.0301214

15. Schlienger RG, Kraenzlin ME, Jick SS, Meier CR. Use of $\beta$-blockers and the risk of fracture. JAMA. 2004 Sep;292(11):1326-32. https://doi.org/10.1001/jama.292.11.1326

16. Rani CS, MacDougall M. Dental cells express factors that regulate bone resorption. Mol Cell Biol Res Commun. 2000 Mar;3(3):145-52. https://doi.org/10.1006/mcbr.2000.0205

17. Ohazama A, Courtney JM, Sharpe PT. Opg, Rank, and Rankl in tooth development: co-ordination of odontogenesis and osteogenesis. J Dent Res. 2004 Mar;83(3):241-4. https://doi.org/10.1177/154405910408300311

18. Pacca SR, de Azevedo AP, De Oliveira CF, De Luca IM, De Nucci G, Antunes E. Attenuation of hypertension, cardiomyocyte hypertrophy, and myocardial fibrosis by $\beta$-adrenoceptor blockers in rats under long-term blockade of nitric oxide synthesis. J Cardiovasc Pharmacol. 2002 Feb;39(2):201-7. https://doi.org/10.1097/00005344-200202000-00006

19. Seow WK. Developmental defects of enamel and dentine: challenges for basic science research and clinical management. Aust Dent J. 2014 Jun;59(1 Suppl 1):143-54. https://doi.org/10.1111/adj.12104

20. Schour I, Massler M. The teeth. In: Farris EJ, Griffth JQ. The rat in laboratory investigation. New York: Hafner. 1949. Vol. 2, p. $104-65$.

21. Pimlott JF, Howley TP, Nikiforuk G, Fitzhardinge PM. Enamel defects in prematurely born, low birth-weight infants. Pediatr Dent. 1985 Sep;7(3):218-23.

22. Goshi LH, Ibidi SM. Distúrbios de cálcio e magnésio no período neonatal. In: Marcondes E. Pediatria básica. 8th ed. São Paulo: Servier; 1994. p. 408-11.

23. Calvi LM, Shin HI, Knight MC, Weber JM, Young MF, Giovannetti A, et al. Constitutively active PTH/PTHrP receptor in odontoblasts alters odontoblast and ameloblast function and maturation. Mech Dev. 2004 Apr;121(4):397-408. https://doi.org/10.1016/j.mod.2004.02.004

24. Elefteriou F, Ahn JD, Takeda S, Starbuck M, Yang X, Liu X, et al. Leptin regulation of bone resorption by the sympathetic nervous system and CART. Nature. 2005 Mar;434(7032):514-20. https://doi.org/10.1038/nature03398

25. Levasseur R, Legrand E, Chappard D, Audran M. Central control of bone mass: potential therapeutic implications. Joint Bone Spine. 2005 Dec;72(6):474-6. https://doi.org/10.1016/i.jbspin.2005.10.002

26. Boggio V, Ladizesky MG, Cutrera RA, Cardinali DP. Autonomic neural signals in bone: physiological implications for mandible and dental growth. Life Sci. 2004 Jun;75(4):383-95. https://doi.org/10.1016/j.Ifs.2003.11.031 